\title{
Anterior abdominal wall endometrioma: a diagnostic dilemma
}

\section{Nilofar Imamhusen Yelurkar*, Meena Naresh Satia, Ananya Rajendra Deekshit, Vijaya Rajesh Badhwar}

Department of Obstetrics and Gynecology, D. Y. Patil Medical College, Nerul, Navi Mumbai, Maharashtra, India

Received: 23 September 2019

Accepted: 25 October 2019

\section{*Correspondence: \\ Dr. Nilofar Imamhusen Yelurkar, \\ E-mail: ntdanwade@gmail.com}

Copyright: $\odot$ the author(s), publisher and licensee Medip Academy. This is an open-access article distributed under the terms of the Creative Commons Attribution Non-Commercial License, which permits unrestricted non-commercial use, distribution, and reproduction in any medium, provided the original work is properly cited.

\begin{abstract}
The presence of functioning endometrium outside the uterine cavity is often encountered in gynaecological practice but an extremely rare entity is its extra pelvic variant is seen sometimes around the umbilicus, anterior rectus sheath vesical region, also rarely seen around the kidney's nasal mucosa, lungs and the pleura. The incidence of this condition is as low as $0.03 \%$ to $0.15 \%$. Endometrioma of the anterior rectus sheath is well documented in literature but because of its rarity may pose a diagnostic dilemma. Reporting herewith a case of anterior rectus sheath endometrioma where medical line of treatment failed and surgical excision was required.
\end{abstract}

Keywords: Endometrioma, Scar endometriosis

\section{INTRODUCTION}

Endometriosis a major gynaecological problem affecting $8-10 \%$ of reproductive age women. It is associated with primary or secondary infertility in $30 \%$ of the young women. ${ }^{1}$ Pelvic endometriosis is common involving organs like the ovaries, uterosacral ligament, pouch of Douglas and the rectosigmoid and also on the site of episiotomy. ${ }^{2}$ Endometriosis though a benign condition can spread in a cancer like fashion and create extensive havoc in the pelvis causing dense adhesion in the pelvis with the bladder in front and the sigmoid colon at the back. Extra pelvic endomatriosis is unquestionably rare and more difficult to diagnose and treat and has certainly been less well studied and reported. The clinical presentation varies from cyclic pain to painful palpable nodules increasing in size during periods \& bleeding from scar which highlight the fact that extra pelvic endometriosis still remains an enigma which is difficult to diagnose requiring high index of clinical suspicion especially when it is recurrent and deep seated in anterior abdominal wall as was noted in the present case. It is easily confused with other conditions such as keloids, hematoma, stitch granuloma, abscess primary or metastatic adenocarcinoma, nodular melanoma, cutaneous endosalpingosis and inguinal and incisional hernia. ${ }^{3}$ Anterior abdominal wall scar endometriomas is most commonly seen after procedures on uterus and tubes as was seen in present case scenerio in which the patient had history of two previous lower segment caeserean sections. Due to increase in the incidence of LSCS rate scar endomatriosis has also increased.

\section{CASE REPORT}

38-year-old patient with history of previous two LSCS came to the gynaecology OPD of a tertiary care centre with complaints of cyclic pain in abdomen during menstrual periods and lump in abdomen at left infra umbilical region since 2 years which increased in size during periods and was associated with tenderness. On clinical examination, a lump of approximately 10x10 cm in the supra-pubic region extending up to the midpoint of umbilicus and symphysis pubis on previous scar site was noted and patient was called for examination during periods Fifteen days later she presented with a tender lump in the abdominal wall which had increased in size. A clinical impression of endometrioma in the parietal 
wall was made and USG examination was advised. On sonography two well defined hyperechoic lesions involving rectus abdominis muscle with connection to the uterus s/o scar endometriosis was present. So, the diagnosis of scar endometriosis was made. FNAC was done which confirmed the diagnosis. Hemosiderin laden macrophages were seen on FNAC report. CECT of abdomen and pelvis was S/O scar endometriosis involving rectus sheath and right rectus abdominis muscle as shown in Figure 1 and 2. Figures CT scan showing anterior abdominal wall endometrioma.

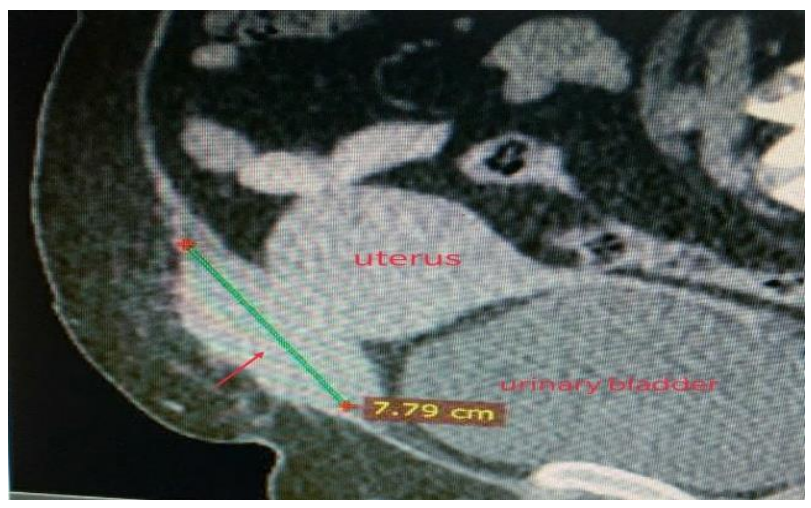

Figure 1: Longitudinal section. Arrow showing endometriotic mass in rectus sheath extending uterine scar.

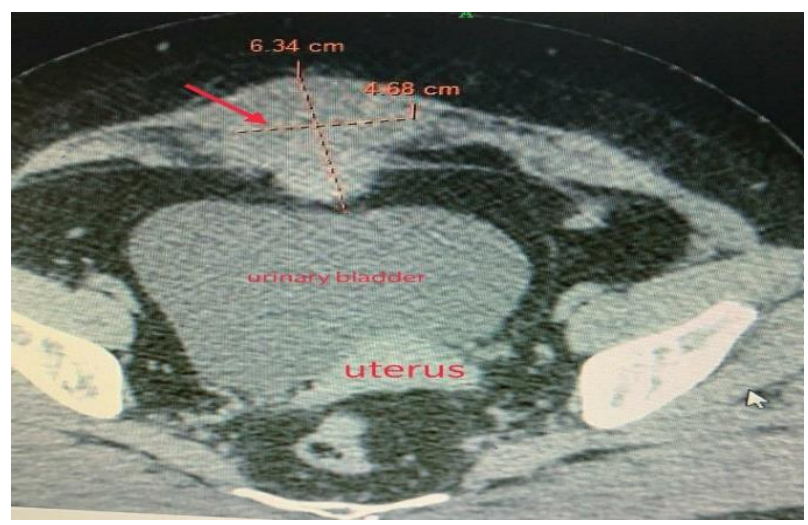

Figure 2: Transverse section. Arrow showing endometriotic mass in rectus sheath.

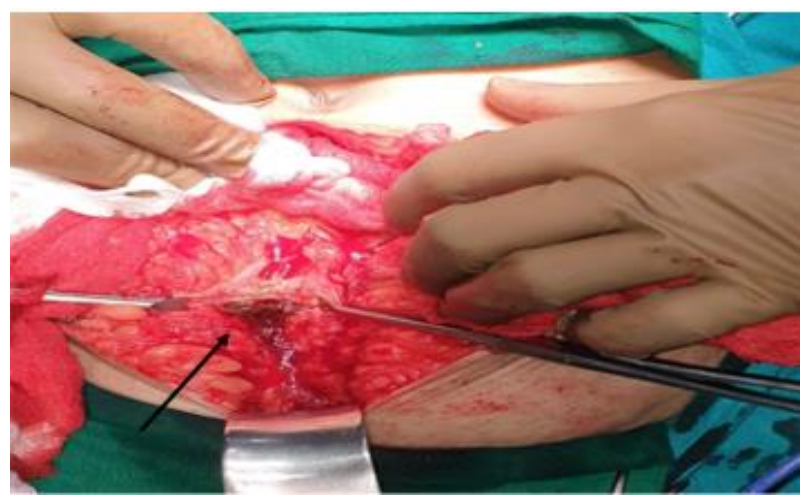

Figure 3: Endometrioma in parietal wall.
Ca 125 levels were elevated to 125 IU. Initially medical line of treatment with Inj. Leuprolide depot $3.75 \mathrm{mg}$ was given to the patient but it failed as she had no improvement in her symptoms and there was no change in size of lesion either, so a descions of exploratory laparotomy was done intraoperative findings were as shown in Figure 3 and 4.

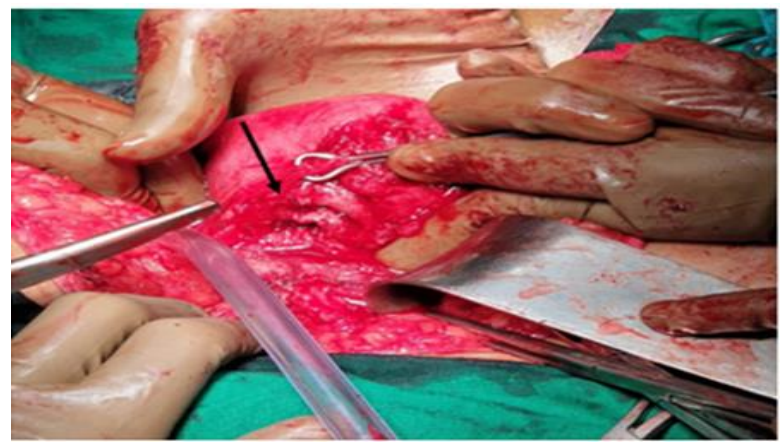

Figure 4: Scar site endometriosis on uterus.

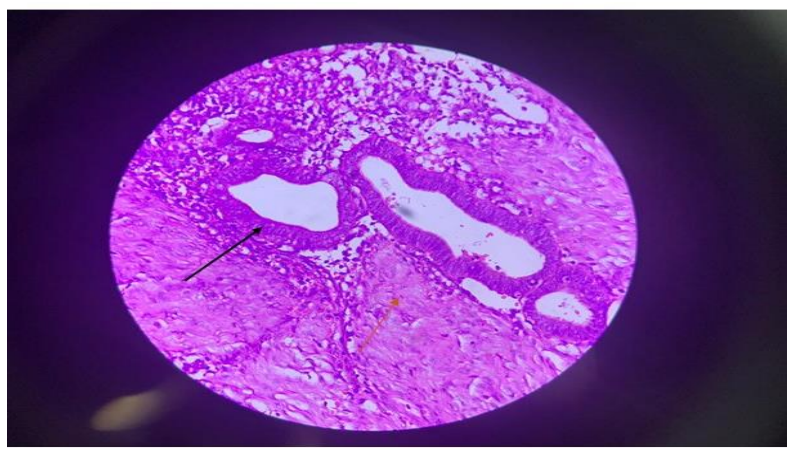

Figure 5: $\mathrm{H}$ and $\mathrm{E}$ 40X.

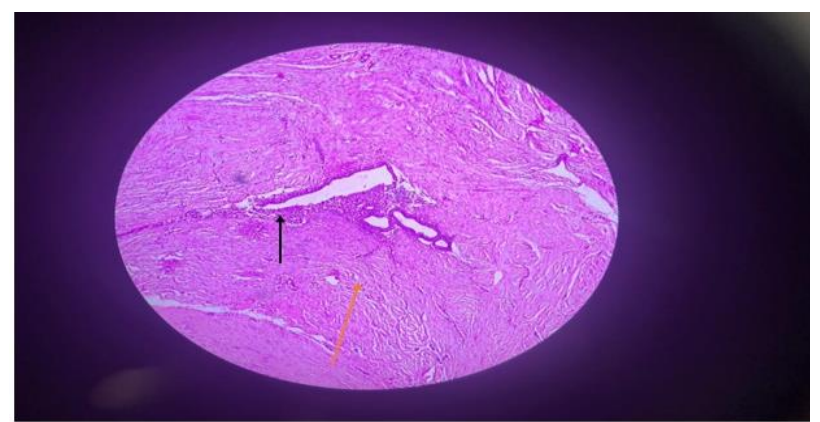

Black arrow showing endometrial glands surrounded by stroma amidst scar tissue shown by red arrow.

Figure 6: $\mathrm{H}$ and E 10X.

Black arrow showing endometrial glands surrounded by stroma amidst scar tissue shown by red arrow.

Uterus was densely adherent to the anterior rectus sheath. The scar of previous two LSCS was dissected which showed chocolate material which was aspirated and lesion was removed. Micro bits in the anterior rectus sheath were cauterised and the isthmus of the uterus was sutured in two layers and covered with surgical to prevent 
adhesion formation. Tubal ligation was done. Anterior abdominal wall muscle reconstruction was done and abdomen was closed in layers postoperative course was uneventful and patient was discharged on $7^{\text {th }}$ postoperative day histopathology report was suggestive of scar endometriosis which showed fibrosis and myometrium with fibrous tissue had endometrial type columnar glands surrounded by endometrial type stroma with no evidence of atypia and malignancy as shown in Figure 5 and 6.

\section{DISCUSSION}

Endometriosis is a relatively common gynaecology problem in women of reproductive age group There are multiple theories for the pathogenesis of this disease but one of them suggests that endomatrial cells transported to the ectopic sites when stimulated by oestrogen may proliferate and become endometriomas which may become symptomtic. ${ }^{4-7}$ Extra-pelvic endometriosis has been described in almost all body cavities but most freqent location is in the abdominal wall and is usually associated with surgeries where uterine cavity has been opened as in LSCS. ${ }^{8-10}$ In general, the characteristic clinical symptom of endometriosis is cyclic pain associated with menses. ${ }^{11,12}$ All Patients with abdominal wall endometriosis usually present with focal abdominal pain which is usually cyclic. Most of the patients present with a palpable mass at the site of maximum tenderness at the surgical scar site ultrasonographic findings of these masses show hypoechoic lesions with internal vascularity on power doppler. These lesions may appear as purely cystic with chocolate material or solid deposits with fibrosis. The imaging appearance might be expected to be more heterogeneous, with frequent cystic changes due to intralesional bleeding associated with menstruation. The differential diagnosis should include neoplasms, such as a sarcoma, desmoid tumor, lymphoma, or metastasis, and nonneoplastic causes, such as a suture granuloma, ventral hernia, hematoma, or an abscess. ${ }^{12,13}$

The MRI images show solid enhancing mass in the abdominal wall. ${ }^{14-16}$ In our patient final diagnosis was made by sonography guided FNAC in which multiple hemosiderin laden macrophages were noted histology is the hallmark of diagnosis. It is satisfied if endometrial glands, stroma, and hemosiderin pigment are seen as was seen in or histopathology image. Medical therapy with danazol, progesterone, and GnRH produces only partial recovery, The success rate of medical line of treatment such as leuprolide depot is low which may offer only temporary relief. The incidence of concomitant pelvic endometriosis with scar endometriosis has been reported to be from $14.3 \%$ to $26 \%$ Ideally, all patients must be examined for concomitant pelvic endometriosis surgical excision is therefore most often required. Local wide excision is accurate treatment of choice for scar endometriosis. Synthetic mesh placement may be required in larger lesions which lie deep to the anterior rectus sheath.

\section{CONCLUSION}

Anterior abdominal wall scar endometriosis poses a challenge for diagnosis and treatment in view of varied manifestations and recurrence, remaining as an enigma. These interesting cases add on to the scientific knowledge as they have an atypical presentation of extra pelvic endometriosis, compelling us to think about the genetic tendency of these patients toward recurrence and need of high index of suspicion for diagnosis, need of follow-up and prevention of recurrence at incisional site.

Funding: No funding sources

Conflict of interest: None declared

Ethical approval: Not required

\section{REFERENCES}

1. Acién P, Velasco I. Endometriosis: a disease that remains enigmatic. ISRN Obst Gynecol 2013;2013:12.

2. Machairiotis N, Stylianaki A, Dryllis G, Zarogoulidis $\mathrm{P}$, Kouroutou P, Tsiamis $\mathrm{N}$, et al. Extrapelvic endometriosis: a rare entity or an under diagnosed condition?. Diag Pathol. 2013;8(1):194.

3. Blanco RG, Parithivel VS, Shah AK, Gumbs MA, Schein M, Gerst PH. Abdominal wall endometriomas. The Am J Surg. 2003;185(6):596-8.

4. Patterson GK, Winburn GB. Abdominal wall endometriomas: report of eight cases. Am Surg. 1999;65:36-9.

5. Koger KE, Shatney CH, Hodge K, McClenathan JH. Surgical scar endometrioma. Surg Gynecol Obstet. 1993;177:243-6.

6. Seydel AS, Sickel JZ, Warner ED, Sax HC. Extrapelvic endometriosis: diagnosis and treatment. Am J Surg. 1996;171:239-41.

7. Dwivedi AJ, Agrawal SN, Silva YJ. Abdominal wall endometriomas. Dig Dis Sci. 2002;47:456-61.

8. Blanco RG, Parithivel VS, Shah AK, Gumbs MA, Schein M, Gerst PH. Abdominal wall endometriomas. Am J Surg. 2003;185:596-8.

9. Simsir A, Thorner K, Waisman J, Cangiarella J. Endometriosis in abdominal scars: a report of three cases diagnosed by FNA biopsy. Am Surg. 2001;67:984-6.

10. Ideyi SC, Schein M, Niazi M, Gerst PH. Spontaneous endometriosis of the abdominal wall. Dig Sur. 2003;20:246-8.

11. Singh KK, Lessells AM, Adam DJ. Presentation of endometriosis to general surgeons: a 10-year experience. Br J Surg. 1995;82:1349-51.

12. Woodward PJ, Sohaey R, Mezzetti TP. Endometriosis: radiologic-pathologic correlation. Radio-Graph. 2001;21:193-216.

13. Wolf C, Obrist P, Ensinger C. Sonographic features of abdominal wall endometriosis. AJR. 1997;169:916-7.

14. Francica G, Giardiello C, Angelone G, Cristiano S, Finelli R, Tramontano G. Abdominal wall 
endometriomas near cesarean delivery scars: sonographic and color doppler findings in a series of 12 patients. J Ultrasound Med. 2003;22:1041-7.

15. Coley BD, Casola G. Incisional endometrioma involving the rectus abdominis muscle and subcutaneous tissues: CT appearance. AJR. 1993;160:549-50.
16. Wolf GC, Kopecky KK. MR imaging of endometriosis arising in cesarean section scar. J Comput Assist Tomogr. 1989;13:150-2.

Cite this article as: Yelurkar NI, Satia MN, Deekshit AR, Badhwar VR. Anterior abdominal wall endometrioma: a diagnostic dilemma. Int J Reprod Contracept Obstet Gynecol 2019;8:5032-5. 